\title{
ANÁLISIS DE UN IMPRESO DE FRANCISCO DE RIOJA SOBRE LA CORRECTA REPRESENTACIÓN DEL TÍTULO DE LA CRUZ DE CRISTO
}

\section{ANALYSIS OF A PRINTED MATTER BY FRANCISCO DE RIOJA ON THE PROPER REPRESENTATION OF THE TITLE OF THE CROSS OF CHRIST}

\author{
M. ${ }^{a}$ Teresa Gacho Muñoz \\ IES Blas de Otero, Madrid. España \\ mgachomunoz@educa.madrid.org
}

\begin{abstract}
Este artículo analiza un impreso que parece haber pasado inadvertido hasta hoy y que recoge los pareceres de Francisco de Rioja y el duque de Alcalá acerca de la correcta representación del título de la cruz de Cristo. El análisis muestra la disputa epistolar de Rioja para demostrar que la inscripción propuesta por Francisco Pacheco es la más adecuada.

Palabras clave: Francisco de Rioja; duque de Alcalá; título de la cruz; Francisco Pacheco; Biblioteca Nacional de España.

This paper analyzes a printed matter that seems to have gone unnoticed by scholars thus far and that includes the opinions of Francisco de Rioja and the Duke of Alcalá on the proper representation of the title of the cross of Christ. This analysis shows the main epistolary arguments of Rioja to demonstrate that the inscription proposed by Francisco Pacheco is the most suitable.

Keywords: Francisco de Rioja; Duke of Alcalá; title of the cross; Francisco Pacheco; Biblioteca Nacional de España.
\end{abstract}

\section{INTRODUCCIÓN}

El objeto de este artículo es presentar un impreso del poeta Francisco de Rioja que parece haber pasado inadvertido hasta hoy ${ }^{1}$. El documento, de $225 \mathrm{x} 155 \mathrm{~mm}$ y

${ }^{1}$ Puede encontrarse más información biográfica acerca de Francisco de Rioja (15831659) en los estudios de MARTÍNEZ DE MERLO, Luis: El grupo poético de 1660: Antología. Madrid, 1992, pp. 32-36; CHIAPPINI, Gaetano: Fernando de Herrera y la escuela 
conservado en la Biblioteca Nacional con la signatura 2/35639, recoge los pareceres de Rioja y el duque de Alcalá acerca de la representación Del titulo de la Cruz de Christo Señor nuestro ${ }^{2}$. En él no consta año de edición ni autor, aunque el catálogo de esta biblioteca lo atribuye al duque de Alcalá, e indica que entre sus páginas figura la fecha de $1619^{3}$.

Este impreso está compuesto por una carta al lector de tres hojas sin numerar de Antonio de Laredo Salazar, secretario del duque de Alcalá. A continuación, una hoja en blanco da paso a las cuarenta restantes que integran el documento: una carta del secretario del duque a v.P., un Papel del duque en respuesta a la propuesta iconográfica del Crucificado de Pacheco -incluye inscripción en hebreo, griego y latín: "HIC EST IESVS NAZARENVS REX IVD."-, una Carta

sevillana. Madrid, 1985, pp. 55-58; LÓPEZ BUENO, Begoña: Poesías. Madrid, 1984, pp. 11-245; BROWN, Jonathan: Imágenes e ideas en la pintura española del siglo XVII. Madrid, 1980, pp. 73-76; COSTE, Jean: Datos útiles para la biografía de Francisco de Rioja. Valencia, 1975, pp. 5-12; DE LA BARRERA Y LEIRADO, Cayetano: Poesías de Francisco de Rioja. Madrid, 1867, p. 179; y LÓPEZ DE SEDANO, Juan Joseph: Parnaso español: colección de poesías escogidas de los más célebres poetas castellanos. Madrid, 1768, pp. xxvi-xxxi.

${ }^{2}$ Los títulos de este documento y el que hace referencia a la respuesta de Francisco de Rioja a las Advertencias, así como los textos que pertenezcan a estos escritos, se recogen a lo largo de este estudio con las peculiaridades lingüísticas, incluidas las presuntas erratas, que aparecen en los impresos consultados en la Biblioteca Nacional de AFÁN DE RIBERA Y ENRÍQUEZ, Fernando: Del Titulo de la Cruz de Christo. Madrid, s. a., con signatura 2/35639, y DE RIOJA, Francisco: Esta respuesta a las advertencias que salieron en Sevilla, contra una carta mia, en que defendi el Titulo de la Cruz, que hizo el Padre Luis de Alcaçar. Impreso. Madrid, s. a., con signatura 2/18771(2).

${ }^{3}$ Existen otras tres copias de este impreso catalogadas en la Biblioteca Nacional como 3/53387, 3/63244 y 2/35639; otra en la Real Biblioteca con signatura VIII/280, y una más en el Museo Nacional del Romanticismo de Madrid LL-II-11(2). La Biblioteca Capitular y Colombina de Sevilla cuenta con otro ejemplar, catalogado como 17-2-2, y en la Biblioteca General de la Universidad de Sevilla se conserva otro bajo la signatura 111/025(10). La Biblioteca Pública del Estado en Huesca contiene un volumen catalogado como B-17-1731, y la Biblioteca Pública del Estado en Mallorca cuenta con otro bajo la signatura 24068. La Universidad de Barcelona cuenta con tres ejemplares con las signaturas C-249/5/37, B-10/3/11 y C-222/6/1, y en la Biblioteca Pública Episcopal del Seminario de Barcelona se conserva otro ejemplar catalogado como R.1149. Finalmente en la Biblioteca Pública del Estado "Fernando de Loazes" de Orihuela se conserva un ejemplar más con la signatura 2413. Debe señalarse también que dos de los textos de la polémica están copiados en los Tratados de erudición de varios autores (Biblioteca Nacional de España, ms. 1713), que recopiló Francisco Pacheco. Los mencionados textos son el Papel del duque, dirigido a Pacheco (23r-26v), y la Carta de Francisco de Rioja a Francisco de Pacheco (28r-33r). 
de Francisco de Rioja a Francisco de Pacheco, y unas anónimas Advertencias a la carta de Francisco de Rioja 4 .

Debe señalarse la presencia de una variante del impreso: Esta respuesta a las advertencias que salieron en Sevilla, contra una carta mía, en que defendí el Titulo de la Cruz, que hizo el Padre Luis de Alcaçar, catalogada por la Biblioteca Nacional como 2/18771(2). La Biblioteca asigna a Rioja este documento de 167 x 231 $\mathrm{mm}$, que cuenta, junto con las partes mencionadas, con una hoja plegada de 225

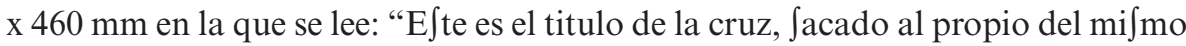
que $\int$ ta en la $\int a n c t a$ cruz en Roma y de $\int$ de la raya colorada adelante le faltaua" y un anexo de menor formato 205 x $147 \mathrm{~mm}$, que probablemente se imprimió por separado y fue unido al resto del impreso mediante un cordel en una posterior encuadernación de la Biblioteca Nacional. Consta de 14 páginas que contienen una carta de Francisco de Rioja al conde duque de Olivares y la respuesta de Francisco de Rioja a las Advertencias contra su carta ${ }^{6}$.

El objetivo de esta relación epistolar gira en torno a la defensa del rigor iconográfico en la representación del título de la cruz, para lo que, frente a las réplicas que sostienen el error en la inscripción hebrea y la ausencia del artículo hic, Rioja apoya lo contrario como lo más fidedigno. Para ello aporta en sus contrarréplicas ejemplos de textos y antiguas representaciones que no solo sirvieron en su época para sustentar su tesis, que acreditaba la iconografía propuesta por Pacheco y que influyó en las futuras representaciones de Velázquez -ejemplo por excelencia que ilustra el universo ideológico de las austeras representaciones del Crucificado en la pintura del Siglo de Oro español-, sino también para demostrar la importancia que aquellos temas adquirieron en los círculos culturales del Siglo de Oro y, en definitiva, para enriquecer los estudios sobre la iconografía de la crucifixión.

En cuanto al origen de este impreso, debe situarse en el ambiente de las tertulias que tuvieron lugar en el Siglo de Oro español, concretamente en las que se realizaron en la Academia de Pacheco, donde el propio Rioja "discutía en amigable controversia los más delicados puntos de arte y de literatura” con Juan

${ }^{4}$ AFÁN DE RIBERA Y ENRÍQUEZ, F.: Del Titulo de la Cruz de Christo, op. cit., pp. 1r-40r.

${ }^{5}$ DE RIOJA, F.: Esta respuesta a las advertencias..., op. cit., pp. 4r-43r.

${ }^{6}$ La Real Biblioteca cuenta entre sus fondos con un documento similar a esta variante, también asignado a Francisco de Rioja. Se trata del manuscrito Pareceres del Duque de Alcalá y Francisco de Rioja sobre el título de la Cruz de Cristo, II/571. Este manuscrito de 302 x $205 \mathrm{~mm}$ fue copiado en el siglo XVIII -lo que indica que es copia de alguno de los impresos de 1619-. Cuenta con una hoja plegada de 298 x $465 \mathrm{~mm}$ que recoge el título de la cruz de la iglesia de la Santa Croce, pero no contiene el anexo del impreso 2/18771(2). Por todo esto se cita según el impreso. 
de Salinas y Castro, Arguijo, Francisco de Medina, Baltasar de Alcázar y Rodrigo $\mathrm{Caro}^{7}$.

Estos puntos de encuentro resultaron claves para desarrollar la colaboración entre los artistas y sus respectivos trabajos: una muestra de lo muy vinculadas que estaban la creación poética y artística es el hecho de que Pacheco realizó la cartela de la portada del manuscrito de 1614 en el que se recogen los versos de Rioja, mientras que el poeta, participó hasta en cinco ocasiones con sus escritos en el Arte de la pintura ${ }^{8}$. Bassegoda indica cómo esto resalta el papel de Rioja como el asesor cultural de más confianza de Pacheco tras la muerte de Francisco de Medina en 1615, y así justifica su frecuente presencia en el tratado de Pacheco'.

Según lo expuesto, Rioja aprobaba el rigor iconográfico de Pacheco, y el ejemplo más claro lo constituye la polémica aprobación del Crucificado de cuatro clavos de $1614^{10}$. Es muy posible que Pacheco exhibiera este nuevo Crucificado y pidiera por escrito pareceres a sus amigos y consultores ${ }^{11}$. Y en este contexto se estudian las dos aportaciones más famosas de Rioja al tema de la crucifixión: por un lado su defensa del Cristo crucificado con cuatro clavos, y por otro lado sus observaciones acerca de la representación del título de la cruz que se han comentado. Si bien es cierto que la primera de estas aportaciones es muy famosa, debido a que Pacheco recoge en su Arte de la pintura la carta que el poeta le envía en 1619 para mostrar su total conformidad con el modelo iconográfico propuesto ${ }^{12}$, no ocurre lo mismo con la segunda, que resulta ser algo menos conocida debido, en gran parte, al mutismo que guarda Pacheco respecto a ella en su ya citado estudio sobre el Arte de la pintura. Sin embargo, no cabe duda de que esta segunda aportación es tan demostrable como la primera, dada la correspondencia que la prueba, y que constituye el impreso objeto de este artículo. La presencia de este documento y la falta de estudios sobre él, demuestra su caída en el olvido por parte de la comunidad investigadora, y justifica la necesidad de artículos que traten de llenar el vacío que se ha generado en este campo de investigación.

${ }^{7}$ SÁNCHEZ, José: Academias literarias del Siglo de Oro español. Madrid, 1961, p. 208.

${ }^{8}$ DE LA BARRERA Y LEIRADO, Cayetano: Poesías de Francisco de Rioja. Madrid, 1867, p. 179.

${ }^{9}$ BASSEGODA I HUGAS, Bonaventura (ed.): Arte de la pintura. Madrid, 1990, p. 28.

${ }^{10}$ Sobre la polémica del número de clavos con que debía representarse al Crucificado véanse los capítulos quince y dieciséis del tercer libro de PACHECO, Francisco: Arte de la pintura. Madrid, 1990.

${ }^{11}$ BASSEGODA I HUGAS, B.: Arte de la pintura, op. cit., p.18.

12 PACHECO, F.: Arte de la pintura, op. cit., p. 719. 


\section{LA REPRESENTACIÓN DEL TÍTULO DE LA CRUZ DE CRISTO}

Señalada la importancia de estas aportaciones de Rioja a las propuestas iconográficas de la crucifixión barroca, e indicada la falta de estudios sobre los citados impresos acerca de la representación del título de la cruz, pueden presentarse los principales argumentos que se defienden en estos documentos, y así comprobar sus repercusiones iconográficas.

La polémica entre Rioja y el duque de Alcalá acerca de la correcta representación del letrero sobre la cruz se inició como consecuencia de una carta que Rioja envió a Pacheco ${ }^{13}$. La epístola respondía al requerimiento, por parte de Pacheco, de una aprobación iconográfica de Rioja sobre el título de un Crucificado que había pintado y que había sido criticado por el duque de Alcalá. La aprobación del poeta supuso su enfrentamiento con el duque.

Los datos que se conservan acerca de lo sucedido y cómo se zanjó la situación no son muy precisos, puesto que la polémica surgió a raíz de unos manuscritos que ambos personajes intercambiaron y, aunque posteriormente -debido al interés que suscitó la cuestión- dichos manuscritos se terminaron imprimiendo, esto no basta para aclarar la manera en que sucedieron los hechos, y más confuso se presenta aún el desenlace de estos, ya que Pacheco tan solo lo refleja parcialmente en sus Tratados de erudición, y no llega siquiera a mencionarlo en su tratado definitivo dedicado al Arte de la pintura. Ante este silencio bibliográfico del principal testigo y causante del conflicto, Bassegoda conjetura sobre la posibilidad de que Pacheco buscara un modo de obtener información acerca de la aceptación de su propuesta artística preguntando a diferentes entendidos. Uno de los consultados fue el duque de Alcalá, quien aceptó la propuesta de los cuatro clavos, pero no la del título de la cruz, que había sido sugerido por Luis del Alcázar ${ }^{14}$, según una reconstrucción a partir de las reliquias de la Santa Cruz conservadas en la basílica romana de la Santa Croce in Gerusalemme. Esta propuesta, aprobada también por Rioja, fue objeto de objeciones que el duque de Alcalá formula en su epístola del 1 de abril de 1619. Rioja respondió a este ataque mediante una carta a Francisco Pacheco, fechada el 20 de abril de 1619. El 1 de mayo de 1619, un personaje anónimo, que no es el duque, escribe una réplica titulada Advertencias del Duque

13 AFÁN DE RIBERA Y ENRÍQUEZ, F.: Del Titulo de la Cruz de Christo, op. cit., p. 7 r.

${ }^{14}$ El jesuita sevillano Luis del Alcázar (1554-1613) destacó por su Vestigatio arcani sensus in Apocalypsi (1614), publicado después de su muerte. Se contaba entre las amistades de Pacheco, es uno de los ingenios que figura en su Libro de retratos, y sus sugerencias teológicas sobre la iconografía llegaron a ejercer gran influencia sobre el pintor. Puede encontrarse más información biográfica en OLIVARES, Estanislao: Luis del Alcázar (15541613). Datos biográficos. Sus escritos. Bibliografía. Madrid, 1989, pp. 5-50. 
a la Carta de Francisco de Rioja. Esta réplica encontró una contra-réplica de fecha indeterminada y cuya autoría pertenece a Rioja: Respuesta de Francisco de Rioja a las advertencias contra su carta, con la cual finaliza el debate ${ }^{15}$.

\section{CARTA DEL DUQUE DE ALCALÁ EN RELACIÓN CON EL CRISTO DE PACHECO}

El duque comenta que el Cristo que vio en casa de Pacheco presentaba "defectos" que habían sido transcritos por Pacheco de un pergamino en el que se leía: "E te titulo es el mejor de todos: diolo el Padre Luys de Alcaçar; aprobolo

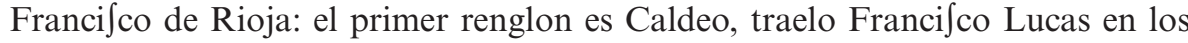
Comentarios a los Evangelios, menos el articulo del principio, que dice Hic, en

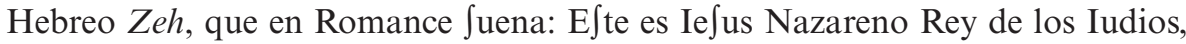
añadido de San Lucas"16.

Al parecer, este pergamino no convenció al duque, quien continuó insistiendo en los errores del título, concediendo especial importancia a dos: en primer lugar, lo inapropiado de introducir el artículo latino hic al principio, por ser una novedad nunca vista hasta el momento: "Lo primero, en que (a mi parecer) $\int$ e deve reparar, es en el articulo Hic del principio: porque $\int i$ bien el $\int e n t i d o$ fue, que el que alli padecia era Ie us Nazareno; qualquiera novedad en materia

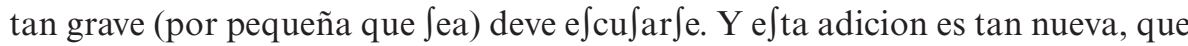

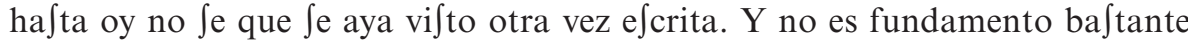
dezir, que se tomò de San Lucas: porque los Evangelistas, llegando el titulo de

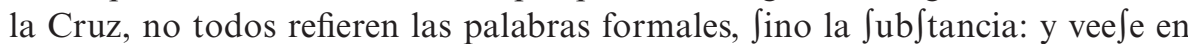

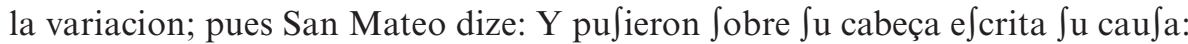

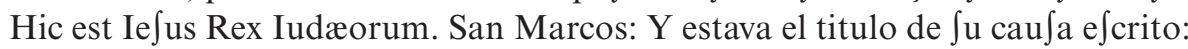
Rex Iudæorum. San Lucas: Y e $\int$ tava encima una in $\int$ cripcion con letras Griegas, Latinas, y Hebreas: Hic est Rex Iudæorum. Y ultimamente San Iuan: E fcrivio el

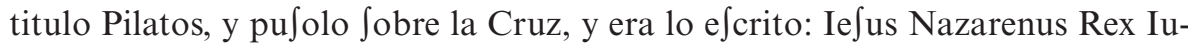
dæorum. Con que tenemos ya, por esta variedad, que (en e te ca $\int o$ ) la formali-

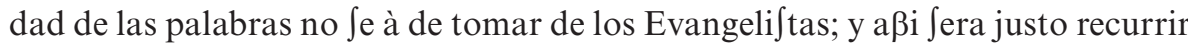
al me $\int$ mo titulo, que la Santa Reyna Elena, madre del Emperador Con $\int \operatorname{tantino,}$ hallò el año de Chrifto 330 "17.

${ }^{15}$ BASSEGODA I HUGAS, B.: Arte de la pintura, op. cit., pp. 18-19.

16 AFÁN DE RIBERA Y ENRÍQUEZ, F.: Del Titulo de la Cruz de Christo, op. cit., p. 3 r.

${ }^{17}$ Ibidem, pp. 3r-3v. 
En segundo lugar, el duque señala la manera en que se realiza la inscripción hebrea, que "eftà de todo punto errada"18. Para sostener su primera afirmación, el duque adujo que al no ser el hic un dato confirmado por la totalidad de los evangelistas - pues tan solo lo citan Mateo y Lucas-, era más acertado recurrir a lo escrito en el propio letrero de la cruz, bien por las relaciones históricas referidas a él de autores como San Anselmo o Sozomeno, o por medio de una observación directa del texto conservado en este, pues según la tradición, Santa Elena encontró el título de la cruz en sus excavaciones en el Gólgota.

Este mismo título fue el que posteriormente se llevó a Roma y para el que Constantino edificó la iglesia de la Santa Croce en Gerusalemme, en la que quedó oculto hasta que un cardenal español, Pedro González de Mendoza, lo redescubrió y lo dejó en esa misma iglesia donde pudo ser admirado por la cristiandad -aún hoy continúa expuesto- de modo que el duque pudo aportar también esta evidencia como prueba material que sustentaba su teoría: "Don Pedro Gonçalez de Mendoça, Cardenal ESpañol, queriendo renovar las paredes de aquella Igle fia, cuyo titulo tenia, hallò el de la Cruz de Chrifto en el hueco de una dellas, todo entero, Sin contener mas que Ie Jus Nazarenus Rex Iudæorum, faltando Jolamente, por injuria del tiempo, las ultimas dos letras"19.

El duque, tras presentar estos argumentos que justifican su defensa de la no inclusión del hic en el título de la cruz, concluye diciendo que si la única razón de incluir este artículo latino es que aparece así mencionado en el evangelio de Lucas, en ese caso también debería obviarse el "Ie Jus Nazarenus", pues este título no aparece en el letrero descrito por el evangelista: "Y si toda la fuerça eftà en que San Lucas dixo: Hic eft Rex Iudæorum, tambien Je pudiera dexar de poner

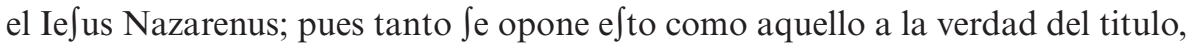
a la autoridad de los Santos, y tradicion de la Iglefia. Sin duda fe dexò por inad-

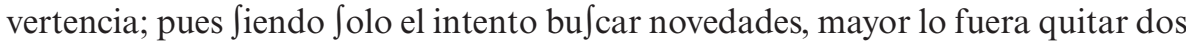
nombres, que añadir un articulo" 20 .

Por otra parte, el duque de Alcalá alude a una confusión de los caracteres hebreos para explicar su segunda afirmación acerca de la errada inscripción hebrea del letrero. Para sostener que la lengua con la que se escribió este título era griego puro -y no cualquier otro tipo de derivación o vulgarismo de esta lengua-, recurre a la mención de este dato por parte de los evangelistas -especialmente Lucas, a quien primero cita para asegurar que el título fue escrito "con letras Griegas, Latinas y Hebreas" ${ }^{21}$, y de quien posteriormente se sirve para explicar:

\footnotetext{
${ }^{18}$ Ibid., p. 5 r.

19 Ibid., p. 4r.

${ }^{20}$ Ibid., p. $4 \mathrm{v}$.

${ }^{21}$ Ibid.
} 
"Literis Hebraicis, dize San Lucas, o ya que de las que primero usò aquella gente, o bien de las que comunmente $\int \mathrm{e}$ ervian entonces para $\int \mathrm{u}$ comunicacion"22-, a los santos -"Las letras del titulo eran Hebreas, como confta de los Evangeliftas y fantos" ${ }^{23}$, o declaraciones más recientes como las del cardenal Baronio, quien, en opinión del duque, insinuó lo siguiente: "Latina lingua cum Hebræa, \& Græca,

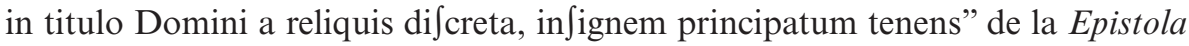
de Nicolao Papa al Emperador Michael del tomo tercero de los concilios ${ }^{24}$.

\section{CARTA DE FRANCISCO DE RIOJA A PACHECO}

No tardó la réplica de Rioja al duque de Alcalá, en la que el poeta se reafirmaba en lo que dispuso en primer lugar, y manifestaba su deseo por restaurar su reputación, dañada tras la carta del duque con sus denuncias hacia los errores que el poeta había pasado por alto en el título de la cruz cuando dio su apro-

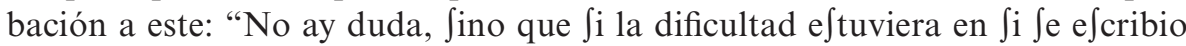
en lengua Hebrea, o no, el titulo de Chrifto, yo callara: porque en las cofas

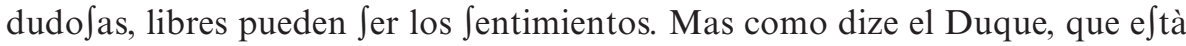
errado, y que tiene letras mas, es obligacion forço a bolver por la reputacion" 25 .

Esta respuesta consta de diez alegaciones en las que Rioja se defiende de las dos principales acusaciones, y reconoce -en la primera alegación- que dentro del escrito griego "eftà errada la ultima diccion", aunque justifica que no es porque así lo escribiera Luis del Alcázar, sino por "yerro de quien trasladò el papel"26.

Rioja dedica dos de sus alegaciones al tema de los caracteres hebreos. En primer lugar, el poeta explica en su segunda alegación, que "el titulo es Syriaco, y efcrito en la lengua vulgar que hablava Ie $\int u$ Chrifto, y los Hebreos, menos la primera diccion, que es Hebrea" 27 . Respecto a esta "primera diccion" Rioja añade que sí que se persuadió de su presencia cuando aprobó el texto: "la qual yo no quife mudar (aunque $\int e$ deviera) por el autor. De manera que efte yerro no me puede parar perjuyzio en la aprobacion, porque yo hablè con puntualidad en el cafo" 28 .

\footnotetext{
${ }^{22}$ Ibid., pp. 5r-5v.

${ }^{23}$ Ibid., p. 5 r.

24 Ibid.

${ }^{25}$ Ibid., p. $7 \mathrm{v}$.

${ }^{26}$ Ibid., p. 8r.

${ }^{27}$ Ibid.

${ }^{28}$ Ibid.
} 
Posteriormente retoma este tema con la décima alegación, con el fin de aclarar que la denuncia del duque no tiene ningún fundamento, pues habiendo sido escrita por Luis del Alcázar en la mencionada lengua vulgar que habló Cristo, "si quiere dezir el Duque, que aviendo de Jer Hebrea, eftà errada, dize bien; pero

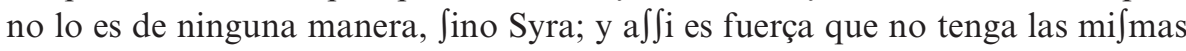
letras" $" 29$.

Rioja justifica la decisión de Luis del Alcázar por hacer uso de esta lengua

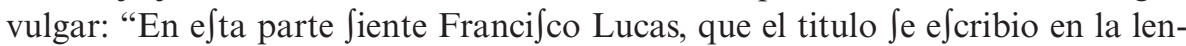
gua vulgar de entonces; y parece mas conforme a razon: porque en $\int u$ opinion dellos, era infcripcion de un jufticiado facinorofo; y es de creer, que antes avia de

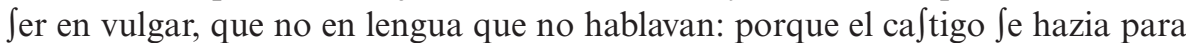
e $\int$ carmiento de la plebe; y la caufa $\int e$ avia de poner en lengua que entendie $\iint e n$ todos: lo que no $\int$ ucediera en una in $\int$ cripcion de obra publica, que jiempre $\int \mathrm{e}$ haze en la lengua mas general, y mas eftimada, y que à de tener mas duracion: porque $\int e$ haze para la memoria venidera. (...) Por e to me parece que el titulo

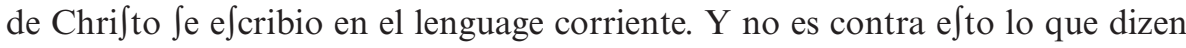
los Evangeliftas: porque aunque diga Hebraicè San Iuan, quiere dezir, en la lengua que hablaron los Hebreos; como fe colige de muchos lugares, en que dizen los Evangeliftas, Hebraicè, y ningunas de las palabras que refieren Jon Hebreas, fino Syras. De manera que como en e ftos lugares no quiere dezir fino en la lengua que hablavan los Hebreos: a $\iint i$ quando lo dize en el titulo, fe deve entender de la mifma manera" ${ }^{30}$.

En cuanto a la defensa de la legitimidad de incluir el artículo hic, esta se desarrolla a lo largo de las siete alegaciones restantes, y se centra en demostrar que no es cierta la afirmación del duque cuando asegura que es una novedad; que la "autoridad" de este artículo está respaldada por su presencia en

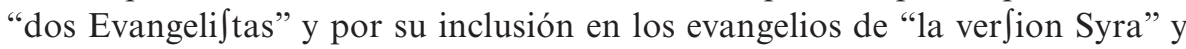
"los Evangelios Arabes"; que el hecho de que este artículo se cite unas veces y otras no, no implica necesariamente su carácter erróneo ${ }^{31}$; que el discurso de Sozomeno, no debe considerarse porque "no eftà bien traduzido" 32 ; y que finalmente ni existe disposición alguna en el Concilio segundo Niceno que apruebe o condene la inclusión del artículo, ni tradición eclesiástica que la respalde como buena o mala práctica ${ }^{33}$.

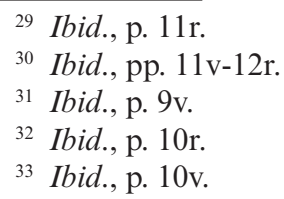


Así, retomando la primera de las cuestiones citadas, Rioja responde a las afirmaciones del duque con ejemplos en los que el hic ha sido escrito en el pasado: "como el padre Iuan Maldonado lo dice en San Mateo: (...) Hic est Ie Jus Nazarenus Rex Iudcerum. (...) tambien lo dize Nono Panopolitano: en la Parafrafis de san Iuan (Cap. 19). (...) Hic est Iudaorum Rex Galilaus Ie Jus; (...) el autor de los Comentarios en San Mateo (entre las obras de San Anselmo): Hic est Ie Jus Nazarenus Rex Iudaorum" 34 .

Rioja dedica sus alegaciones cuarta y quinta al asunto del respaldo de la "autoridad" del artículo hic: en la quinta expone que a "lo que dizen dos

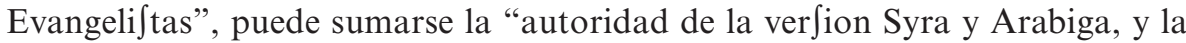
de otros e $\int$ critores" para poner este título. En la cuarta, expone que "confirma

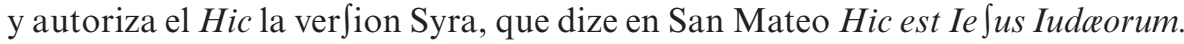
En San Marcos Hic e t t Rex Iudcorum. San Lucas Hic est Rex Iudaorum. San Iuan Hic eft Ie Jus Nazarenus Rex Iudcorum. De manera que el interprete Syro puso el Hic en los Evangelios que lo tienen y en los que no" 35 . Muestra también en este punto los ejemplos de los Evangelios Árabes que se estamparon en Roma con versión interlineal latina: "tambien tienen el Hic en todos quatro tex-

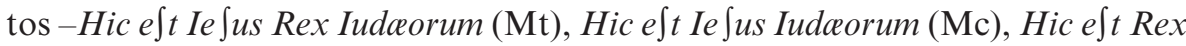
Iudaorum (Lc), Hic est Ie Jus Nazarenus Rex Iudaorum (Jn)-"”36.

En lo que se refiere a la presencia o ausencia del artículo en los diferentes textos conservados, Rioja asegura que "la variedad no es contradicion"37. Y respecto al discurso de Sozomeno que demostraría lo inapropiado de introducir el artículo, Rioja esgrime la evidencia de una mala traducción al aportar el texto en griego, demostrando que "ninguno [...] vio el titulo que hallò la Reyna, ni habla tan apretadamente en el cafo, que apruebe, o repruebe el Hic" 38 .

Para concluir con esta explicación de las alegaciones de Rioja para la defensa de la legitimidad del artículo hic, debe añadirse cómo Rioja comenta que el Con-

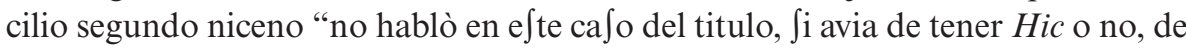
ninguna manera" 39 , y que tampoco existe tradición eclesiástica alguna que sus-

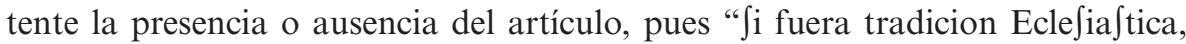

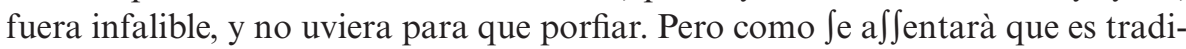

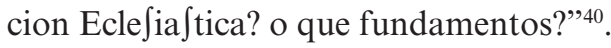

\footnotetext{
${ }^{34}$ Ibid., pp. 8v-9r.

${ }^{35}$ Ibid., p. 9 r.

${ }^{36}$ Ibid., p. $9 \mathrm{v}$.

37 Ibid.

${ }^{38}$ Ibid., p. 10v.

39 Ibid.

40 Ibid.
} 
Por lo tanto, una vez demostradas todas estas evidencias, Rioja indica a Pacheco que si lo que busca es "la puntualidad" del título, que al escribirlo "quite el Zeh, que es diccion Hebrea, y ponga[la] Syra, tambien como lo es el titulo"41, y concluye: "He dicho, que la in $\int$ cripcion no es Hebrea, ni $\int e$ pretendio que lo fue $\int$ e: y que para guardar la puntualidad Syra, no le falta, ni le Jobra letra, a mi parecer: y que el Hic no tiene mucha novedad. En lo demas que pertenece a opinion, libre puede $\int$ er el $\int e n t i m i e n t o " 42$.

\section{ADVERTENCIAS A LA CARTA DE FRANCISCO DE RIOJA Y RESPUESTA DEL POETA}

Las declaraciones de Rioja encontraron una contrarréplica en unas Advertencias de autoría anónima que alentaron ciertas especulaciones acerca de la verdadera identidad del personaje que se escondía tras el anonimato y los motivos que le pudieron llevar a actuar así. Bassegoda no relaciona al duque de Alcalá con el posible autor de estas Advertencias, y comenta que de su misma opinión es González Moreno, quien ha señalado a este tercer personaje como Manuel Sarmiento de Mendoza ${ }^{43}$-aunque las razones de esta hipótesis no llegan a exponerse $-{ }^{44}$. Finalmente, pese a que Bassegoda no lo crea posible, reconoce que no se puede descartar tampoco la posibilidad de que "el Duque utilizara el subterfugio literario de un personaje interpuesto para no rebajarse a discutir directamente con alguien de inferior rango social al suyo" 45 . Por su parte, Rioja tampoco habría podido contestar al duque si este hubiese sido el autor confeso de estas Advertencias, pues como él mismo reconoce en la dedicatoria al conde duque de Olivares -que encabeza su respuesta a las Advertencias-, la prudencia y su razón se lo hubieran impedido ${ }^{46}$.

En cualquier caso, la identidad del autor de las Advertencias no es tan importante para los objetivos de este estudio como los puntos centrales que este documento abordó y los nuevos argumentos que tuvo que esgrimir Rioja para

${ }^{41}$ Ibid., p. $12 \mathrm{v}$.

42 Ibid., p. 13 r.

${ }^{43}$ Manuel Sarmiento de Mendoza (1560-1630) fue canónigo magistral de Sevilla desde 1600. Puede encontrarse información biográfica sobre este teólogo y predicador en los estudios de NÚÑEZ BELTRÁN, Miguel Ángel: La oratoria sagrada de la época del Barroco: doctrina, cultura y actitud desde los sermones sevillanos del siglo XVII. Sevilla, 2000, p. 66.

${ }^{44}$ BASSEGODA I HUGAS, B.: Arte de la pintura, op. cit., p. 19.

${ }^{45}$ Ibidem.

${ }^{46}$ DE RIOJA, F.: Esta respuesta a las..., op. cit., pp. 1r-1v. 
defender su postura. Estos debieron de ser tajantes porque el conflicto acerca del "Título de la cruz" se vio zanjado definitivamente con ellos.

Entre las principales Advertencias, los puntos en que se vuelve a concentrar el peso de la polémica son los que reiteran la inconveniencia de incorporar el artículo latino hic en el título de la cruz; y los que defienden la corrección del uso del hebreo puro en el título, frente a la errónea utilización de una versión vulgar de esta lengua. A raíz de estos dos temas principales se tratan otros, también aludidos en los escritos precedentes, como la "inteligencia" de recurrir a los historiadores, a la autoridad de los escritos, y la tradición eclesiástica.

En primer lugar el anónimo autor de las Advertencias muestra su desconcierto ante la confesión de la primera alegación de Rioja -en ella el poeta reconocía que dentro del escrito griego estaba errada la última dicción, no porque así lo escribiera Luis del Alcázar, sino por "yerro de quien trasladò el papel"47 -, y plantea abiertamente cómo, siendo conocedor Rioja de esta errata, continúa defendiendo su posición. Ante esta pregunta, Rioja explica: "los ierros que io confie $\iint o$, Jon los que tenia el papel del Duque, antes que lo imprimiera; i aviendolos emendado, de $\int$ pues que io los adverti, dize, que cōfe $\iint a n d o$ io, que e $\int$ tâ errado el Titulo, no $\int a b e \int$ obre $\tilde{q}$ se pleitea" 48 . Sobre esta base, Rioja continúa la deducción hasta volver en contra de su anónimo oponente sus propios argumentos: "El Titulo

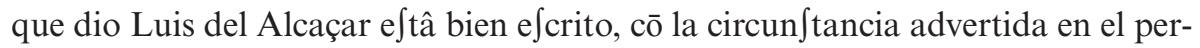
gamino; trasladólo el Duque, i errolo, poniendo en la ultima dicion Sira, en vez de he, daleth, i en la primera Griega, quitando el omicron; de manera que dezia, houts, deviendo decir houtos. A $\int$ si que los ierros que io dige, e $\int$ tan en el papel de mano, que embió el Duque a Francifco Pacheco"49.

Respecto a la introducción del artículo hic, las Advertencias tratan de excusar al duque sugiriendo la posibilidad de que este, al manifestar no haberlo visto escrito así, estuviese refiriéndose a "e ecrita Jobre un titulo de Cruz". Sin embargo, pese a esta puntualización, Rioja continúa mostrándose escéptico, pues para mantener una afirmación tan tajante como esa, es necesario tener una certeza absoluta acerca del contenido de todos y cada uno de los títulos que se han pintado desde el momento de la crucifixión hasta el momento en el que se realiza

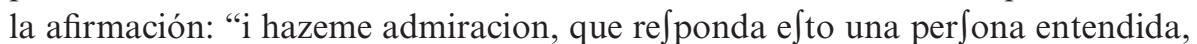

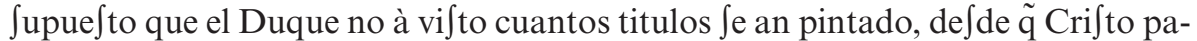
decio, hafta aora: i de los que puede deponer Jolamente, es de los que ai en e fta edad; i cuando todos no tengan hic, dire io, que los pintores no an pintado bien,

\footnotetext{
${ }^{47}$ Ibidem, p. 8 r.

${ }^{48}$ Ibid., p. 2v.

49 Ibid.
} 


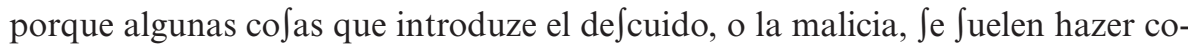
munes de manera, que no $\int \mathrm{e}$ ven, las que pudieren acertar el cuidado"

Así, después de recordar lo que escribe Lucas Tudense acerca de las imágenes de Cristo con tres clavos que introdujeron los Albigenses por malicia ${ }^{51}$, Rioja expresa: "A $\int$ si que es fuerça, que io entendie $\iint e$, que lo que dezia el Duque, era, que no avia autor que lo dige $\iint \mathrm{e}$; pue $\int$ to que no $\int \mathrm{e}$ podian mo $\int \mathrm{trar}$ los Titulos todos de la antiguedad" 52 .

El autor de las Advertencias continúa aportando diferentes razones para desacreditar la presencia del hic en el título de la cruz, y para hacer lo propio con el razonamiento de Rioja que afirma que la parte del título escrita en hebreo está bien escrita: entre las razones que desacreditan la presencia del hic, se encuentran las que restan autoridad a las versiones de los evangelios en lengua hebrea vulgar que introducen este artículo -de manera que se invalida la aportación del dato-; las que privan de credibilidad a Rioja - bien por desdeñar la opinión de los historiadores que no incluyeron el artículo en el título; bien por no considerar al poeta tan docto como a Cristoforsono; o bien por presentar las razones expuestas por Rioja confusas e ininteligibles-; y finalmente las que apelan a la tradición para demostrar la inexistencia del mencionado artículo latino en el título de la cruz.

En cuanto a las razones que desestiman las versiones de los evangelios en lengua hebrea vulgar que incluyen el artículo hic, Rioja comenta cómo la cuarta ad-

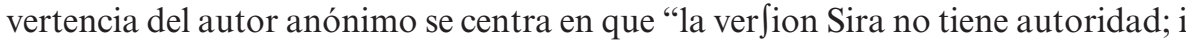
que a $\int$ si no inporta, que e $\int$ té el hic en los quatro Evangelios Siros. Coligelo, de que no $\int$ e $\int a b e$ quien la hizo" 53 . A continuación, Rioja transcribe lo que se aduce en las Advertencias acerca de que estos evangelios se tradujeron y trajeron de Oriente

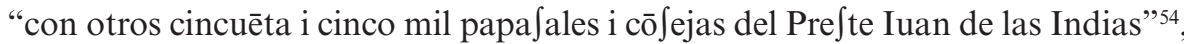

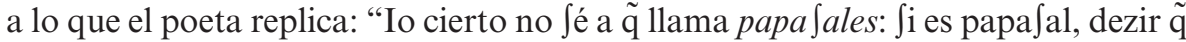
hizo e $\int$ ta ver $\int i \bar{o} \mathrm{~S}$. Marcos, no tiene razō en hablar a $\int \mathrm{si}$; porq̃ es tradiciò de los Si-

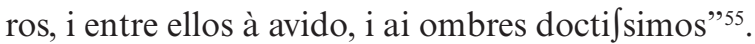

Para asentar sus palabras, Rioja recoge la cita de Francisco Lucas en las notas que hizo a los libros sagrados: "certè in Syriaco Evangelio, quod, viri docti existimant B. Matthæi e $\iint e$ prototypum" 56 . A esto añade que "Io no digo, que tiene la

${ }^{50}$ Ibid., p. 3r.

${ }^{51}$ Sobre las imágenes del Crucificado de tres clavos que introdujeron los albigenses véase PACHECO, F.: Arte de la pintura, op. cit., p. 718.

${ }_{52}$ DE RIOJA, F.: Esta respuesta a las advertencias..., op. cit., p. 3 r.

${ }^{53}$ Ibidem, p. 3v.

${ }^{54}$ Ibid.

${ }^{55}$ Ibid.

${ }^{56}$ Ibid. 
mi $\int m a$ autoridad que la Vulgata, o que los egemplares Griegos, pero de $\int p u e s$, no

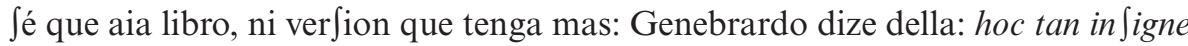

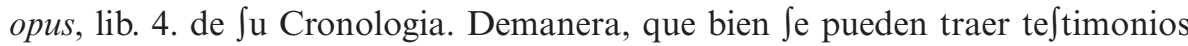

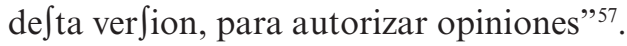

Respecto a las razones que el autor de las Advertencias ofrece para restar credibilidad a Rioja, debe señalarse cómo, en primer lugar, en respuesta a la advertencia sexta -que hace referencia a "que para inteligēcia de los libros Jagrados, fe deve recurrir a los iftoriadores Gentiles" 58 -, Rioja replica: "Io no lo niego en mi papel, ni hablé palabra contra ello. Lo que efcreui es, que diziendo dos Evangeliftas que uvo, hic, aunque todos los iftoriadores del mundo digeran lo contrario, aviamos de pē $\int a r$ que era engaño fuio. I dezir e $\int$ to, no es dezir que no

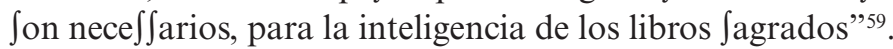

En segundo lugar, y como defensa ante la falta de consideración del autor de las Advertencias, que no reconoce a Rioja tan docto como a Cristoforsono, el poeta responde: "En lo Setimo que advierte, dize que no tiene a mano los egemplares Griegos de Sozomeno; pero que mas Je deve a la autoridad de Iuan

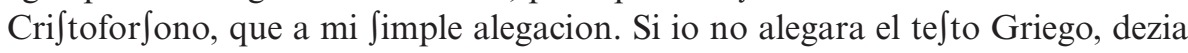

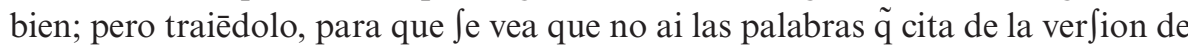

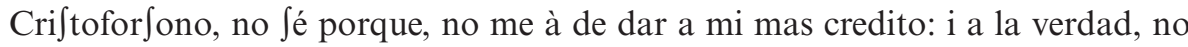
me lo dé a mi, delo al original, que en efto no pido cofa contra razon. [...] En lo

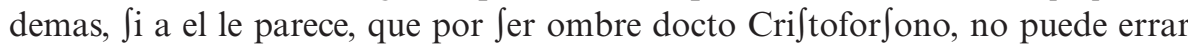
en lo que interpreta, engaña $\int$ e, porque an errado muchos ombres doctos en esta parte" $"$.

A continuación Rioja aporta los ejemplos de errores cometidos por Mateo Radero y Plinio ${ }^{61}$, para después disponer su defensa contra la tercera razón que el autor de las Advertencias presenta con el objeto de desacreditarle. Este nuevo ataque atañe a una supuesta ininteligibilidad de ciertos argumentos del poeta, que Rioja se apresura a esclarecer: "En la Advertencia octava dize, que lo que refiero yo del Concilio, no lo entiende: io procuraré darlo a entender. Dijo el Duque

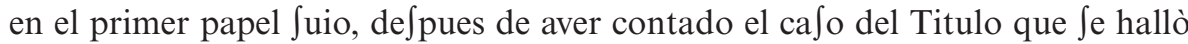
en Santa Cruz de Roma; Con e ta relacion concuerdan las pinturas antiguas, que nue Stros maiores veneraron i aprovaron, a quienes la Setima Synodo iguala en auto-

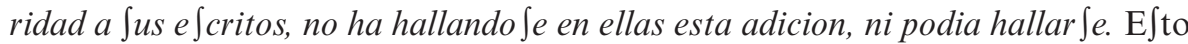

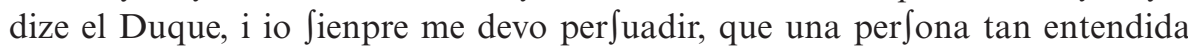

\footnotetext{
${ }^{57}$ Ibid., pp. 3v-4r.

58 Ibid., p. 4r.

59 Ibid.

${ }^{60}$ Ibid., p. 5 r.

${ }^{61}$ Ibid., pp. 5r-5v.
} 


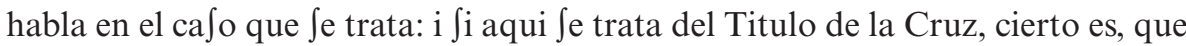
cuando dize: Cōcuerdan con la relacion las pinturas antiguas, a quienes la Jetima

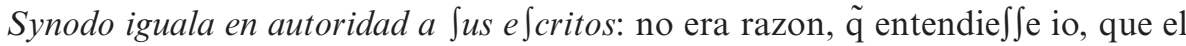
Duque hablava de las imagenes de nueftra Señora, o de S. Pedro i S. Pablo; Jino del Titulo de la Cruz" ${ }^{2}$.

En cuanto al recurso de la tradición, al que el autor de las Advertencias recurre en su noveno punto, como prueba de la inexistencia del artículo hic, Rioja aduce que "habla de la tradicion, i ni la define, ni la de fcrive, que es mucho, para Jaber tāta logica" ${ }^{\prime 3}$. Es el propio Rioja quien define el concepto como: "traditio eft arcana doctrina confuetudine fidelium roborata, ex animo in animum à maioribus in posteros, medio incurrente verbo, tran ffu $\int \mathrm{a}$ " y sentencia: "Es menefter

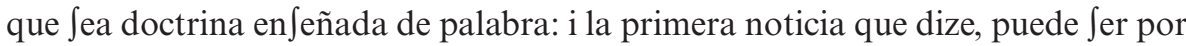
e $\int c r i t o$, i a $\int$ si no es tradicion. Luego infiere, pues $\int i$ la primera, noticia del Titulo,

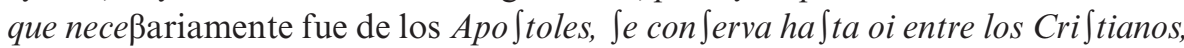

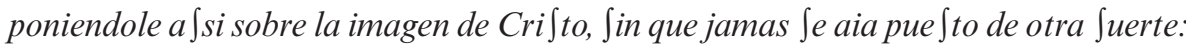
porque no Se puede llamar tradicion a e ta noticia? Lo primero; en vano alega tradicion, en lo que confta por la E Ecritura: porque $\int i$ dizen S. Lucas i S. Mateo, que

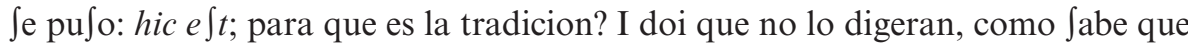

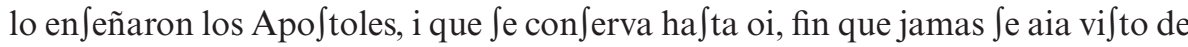

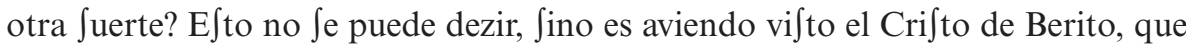
refiere a S. Atanafio, o aviendo vifto todas cuantas imagenes à avido" 64 .

Rioja continúa su explicación comentando cómo todos aquellos elementos iconográficos citados por él se asientan en retratos existentes en Roma o en textos antiguos, pero: "el autor de las Advertencias, no puede moftrar pintura antigua ninguna; i cuando aia alguna medalla, es fuerça $\tilde{q}$ sea de edad baja i tendra

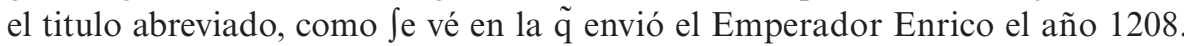
I ia que no ai alguna pintura antigua, citeme un e critor antiguo, que lo diga hablando en la dificultad; porque Ruperto no lo es, que vivia en los años 1119. I no ai para que amontonar autores de $t$ ta edad, que io no negué en mi papel, que avia quien lo dige $\iint \mathrm{e}$; $\int \mathrm{i}$ lo uviera negado, era apropo ito citar, aunque no gente tan moderna, maiormēte, aviendo dicho eftas palabras; $\int i n$ que jamas se

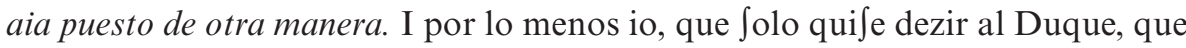
avia quien lo dezia, trage autores de todas edades; porque trage a Jan Mateo, i Jan Lucas, la verfion Arabiga, la Siriaca, a Nono, a Sedulio, al Autor de los

\footnotetext{
${ }^{62}$ Ibid., p. $5 \mathrm{v}$.

${ }^{63}$ Ibid., p. 6r.

${ }^{64}$ Ibid.
} 


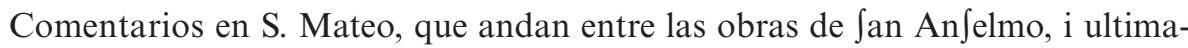
mente a un ombre tan docto, como Iuan Maldonado" ${ }^{65}$.

En cuanto a lo escrito en el pedazo de la tablilla del título de la cruz conservado en la iglesia de la Santa Croce in Gerusalemme de Roma, Rioja manifiesta: "Hagamos pues argumento, de $\int \mathrm{i}$ uvo hic, o no, de un fragmento, donde no Je

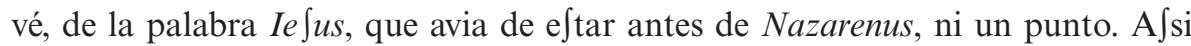
que para averiguar e $\int$ ta dificultad, no ai q̃ citar el Titulo de Sāta Cruz de Roma.

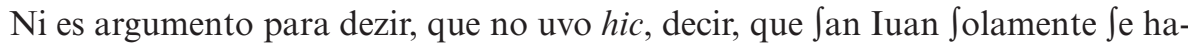
lló junto a la Cruz, que tābien Je hallò en la Cena, i no pone las palabras de la

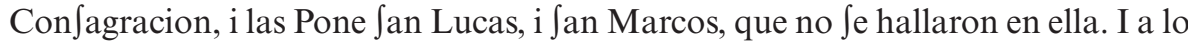
que dize, q̃ ninguno de los Evangeliftas afirma que uvo hic. No Jé que mas claro

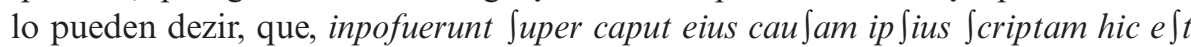

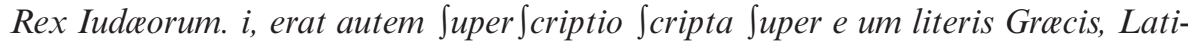
nis, Hebraicis, hic e et Rex Iudcorum" "66.

Por otro lado, respecto a la corrección de la parte del título escrita en hebreo, el autor anónimo termina por reconocer en la décima advertencia una posible mala interpretación por parte del duque. Ante esto, Rioja muestra su satisfacción por haber encontrado la prueba que demuestra la posibilidad de que fuera el propio duque quien interpretó mal el título en hebreo, y no que este estuviera mal

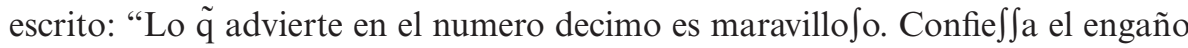
del Duque, i dize: que pudo inferir que la in Soricion del pergamino de Franci $\int c o$ Pacheco, Je puso por Hebrea, de que lo avia de Jer. Io verdaderamente, cuando vi el

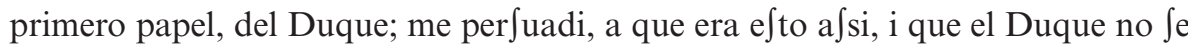
avia enpeñado en e $\int$ crevirlo, fino por parecerle que, como tenia mas letras aquel Titulo que las demas, e tava errado: mas no me atrevi, por la corte $i \mathrm{ia}$, a hablar en

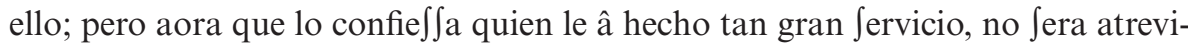
miento repetirlo. Tanbien juzgué, que el Duque no devia aver oido dezir, que $\int e$ e $\int$ crevio en Siriaco, i aunque lo leio en el pergamino, que vio en ca a de Franci $\int c o$ Pacheco, no lo creio, pues dijo; la in Scricion Hebrea, e tá de todo punto errada. Aora dize efte cavallero Jin nombre, que hizo las Advertencias, que como el Du-

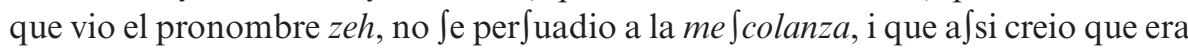
Hebreo el Titulo. Apretadas razones Jon ambas, creer q̃ era Hebreo, porq̃ lo avia de $\int e r$, i porq̃ vio el pronōbre Hebreo" $"$.

Una vez que se señala la evidencia de una posible fisura en los argumentos del duque, Rioja se centra en debilitar más la interpretación de este al indicar cómo incluso el duque no advirtió detalles que en las Advertencias sí se indican: "De

\footnotetext{
${ }^{65}$ Ibid., pp. 6r-6v.

${ }^{66}$ Ibid., pp. 6v-7r.

${ }^{67}$ Ibid., pp. $7 \mathrm{r}-7 \mathrm{v}$.
} 


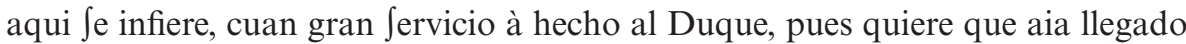

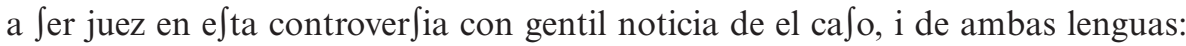
$i$ es de advertir, que de lo que aora dize, del pronombre $z e h$, no habló palabra el Duque antes en $\int u$ papel. De manera, que ni en efto reparò, aun advertido del

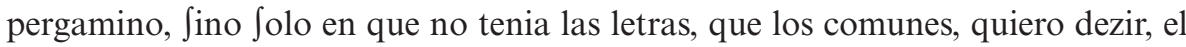
numero. Luego añade, que el Duque no infirio, que el titulo no eftaba en Caldeo.

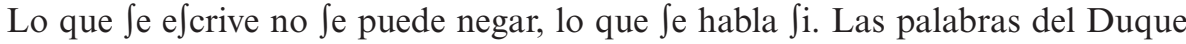
fon eftas: de lo dicho fe colige, que e te renglon primero, como dize el pergamino, que referi, no es Caldeo. I efta con Jequencia que infirio el Duque, bien Je vé, que no $\int e$ puede inferir de las palabras antecedentes. Màs adelante dize, que no fabe, porque e erevi con letras Latinas, lo que el Duque cō Hebreas; pues para diferen-

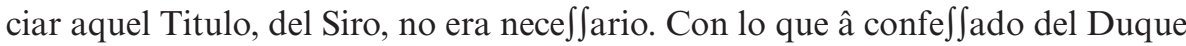
arriba, pudiera io e $\int$ tar de Jobligado a re $\int$ ponder; porque $\int i$ confie $\int a$, que el Duque

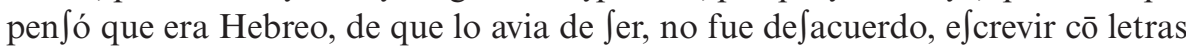
Latinas el Hebreo, i el Siro; porque vie $\iint e$ la diferencia, ia que no la vio en las letras Hebreas" 68 .

Rioja señala cómo el autor de las Advertencias insiste en demostrar que el título de la cruz fue escrito en hebreo puro. Frente a esto, el poeta no puede menos que achacar esta insistencia a una falta de conocimiento acerca de los escritos de Filón, Teodoreto, Oleastro, o Georgio Micael Amira: "Su conclufion es, que el Titulo fue en el Hebreo q̃ habló Adan, porque lo dize el Señor Alfon $\int o$ de Avendaño, como $\int \mathrm{i}$ importa $\iint \mathrm{e}$ algo lo que dige $\iint$ e. Dize el autor no conocido: $i$ la lengua principal, la antigua, la primera, en la que fue e ecrita la Lei, i los Profetas, la en q̃ hablò Adam, quien avra que afirme es la Syra? no deve de aver leido

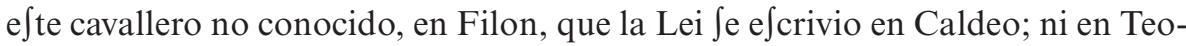
doreto, que Adan habló la lengua Sira; ni que es consfante opinion oi de muchos del Oriente, que fue la primera lengua la Caldea. Oleaftro no trae pocas razones en el undecimo del Genefis; i Georgio Micael Amira Siente que fue la primera la Caldea. E $\int$ to digo, por la admiracion que haze, no porque no $\int i e n t a$ io, que fue la primera lengua la Hebrea. Trae algunos autores, para provar que el Titulo eftuvo efcrito en puro Hebreo; i ninguno dize mas, fino que eftuvo en Hebreo; con que no Se prueva nada, porq̃ Hebrea llamavan a la lēngua Sira" ${ }^{69}$.

Rioja, por su parte, concentra todos sus argumentos en desmontar, una por una, todas estas razones de las Advertencias hasta terminar concluyendo que los errores de los que había sido acusado no eran tales, mientras que los del autor de las Advertencias son cuantos él señala "i otros muchos, que é dejado pa $\int$ ar, por no ponerme a notar todo el papel. Io holgara mucho no aver

\footnotetext{
${ }^{68}$ Ibid.

${ }^{69}$ Ibid., pp. 9r-9v.
}

LABORATORIO DE ARTE 29 (2017), pp. 259-278, ISSN 1130-5762 e-ISSN 2253-8305 - DOI http://dx.doi.org/10.12795/LA.2017.i29.13 
e $\int$ crito e $\int$ to, porque no $\int o i$ inclinado a contender, i menos, con quien e ftà en e $\int$ tado tal, que aun no conoce la calidad de los e fcritores: pero injurias hechas

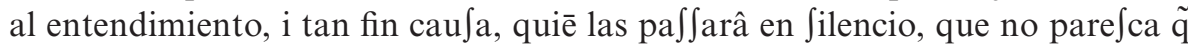
las merece?"70.

\section{INFLUENCIAS DE LAS PROPUESTAS ICONOGRÁFICAS DE FRANCISCO DE RIOJA}

Una vez expuesta la información que ofrecen los documentos, puede plantearse la repercusión que tuvieron, tanto en la teoría como en la práctica. Dentro del campo teórico el mejor exponente es Pacheco, por ser quien originó la disputa, mientras que Velázquez representa el exponente de la praxis de la teoría que defendió su maestro Pacheco. En este sentido debe apuntarse el contraste entre la importancia iconográfica de la disputa sobre la representación del título de la cruz y el poco eco que Pacheco le otorgó a esta cuestión, que pasa desapercibida, eclipsada por el minucioso estudio dedicado en el Arte de la pintura al número de clavos con que se crucificó a Cristo.

En cuanto a Velázquez, debe señalarse que respetó las propuestas iconográficas de Rioja, pero solo en parte en lo referente a la representación de los títulos de la cruz. El Cristo de las Bernardas Reales parece seguir más fielmente el texto propuesto por Pacheco y aprobado por Rioja. De los dos Crucificados es el único que incluye el "este es" en la redacción del mensaje en sus tres lenguas. Es cierto que el letrero se dobla por una esquina, ocultando precisamente algunos de esos caracteres, pero aun así es fácil reconocer en el "IC EST IESVS NAZARÆNVS REX IVDÆORVM" la influencia del título latino de Pacheco "HIC EST IESVS NAZARENVS REX IVD.”.

Las únicas diferencias apreciables son la abreviatura "IVD." que escribe Pacheco en lugar de "IVDÆORVM", y el error ortográfico de Velázquez, al escribir "NAZAR ENVS" en lugar de "NAZARENVS". En cuanto al texto

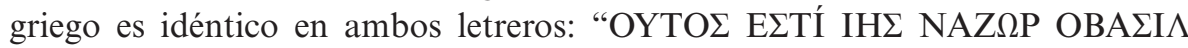
T $\Omega$ NIOY $\Lambda$ AI $\Omega$ N" (salvo en la abreviatura de Pacheco que escribe "T $\Omega$ NIOY $\Lambda$." en vez de "T $\Omega$ NIOY $\Lambda$ AI $\Omega$ N"). Finalmente, es de suponer que en el título en hebreo se incluye el "este es", al igual que se recoge en las otras dos lenguas, e incluso, pese a que esta parte del título está poco definida en la pintura, puede encontrarse cierta similitud entre sus caracteres y los propuestos por el título de Pacheco: "37".

Por su parte, el Cristo crucificado de san Plácido destaca por no presentar el polémico "este es" -en el letrero solo se lee "IESVS NAZÆRENVS REX

\footnotetext{
${ }^{70}$ Ibid., p. $14 \mathrm{v}$.
} 
IVDÆORVM"-. Obviando este detalle, el título coincide en todo lo demás con la fórmula de Pacheco, excepto por los dos errores detectados por Ceballos ${ }^{71}$ : la repetición del mismo error ortográfico que presenta el título latino del Cristo de las Bernardas reales, y otro más relacionado con el título en griego -escribe "NAZOIO $\Sigma$ BA $\Sigma$ I $\Lambda$ EYE" en lugar de "NAZ $\Omega$ P OBA $\Sigma I \Lambda "-$. Respecto a la parte redactada en hebreo, poco puede decirse, excepto que poco tienen que ver con las letras escritas por Pacheco.

Una vez analizados los dos títulos de los Crucificados, lo más destacable -aparte de las incomprensibles faltas ortográficas en un pintor erudito como Velázquez-, es el repentino cambio de la representación del letrero de la Cruz del Cristo de 1631 con su "[H]IC EST IESVS NAZARÆENVS REX IVDÆORVM”, acorde con lo propuesto por su maestro y aprobado por Rioja, al menos preciso “IESVS NAZARÆNVS REX IVDÆORVM” del Crucificado de 1632.

\section{CONCLUSIÓN}

Puede observarse cómo ante todo el interés despertado, el principal impulsor de la polémica sobre el título de la cruz, Pacheco, se mantiene completamente al margen de ella; no recoge su conclusión en el Arte de la pintura -y eso, aun cuando aparentemente la visión iconográfica que se impuso fue la suya (pues fue de Rioja la última palabra que zanjó la disputa)-; e incluso su discípulo, Velázquez, parece evitar el conflictivo título propuesto por su maestro en el Cristo crucificado de San Plácido.

Bassegoda aporta una explicación acerca del silencio del maestro, que, al mismo tiempo, puede encerrar la clave del silencio del discípulo en su Cristo crucificado de San Plácido. Este especialista explica que "esta voluntad de neutralidad" de Pacheco en el conflicto, no hacía sino seguir una hábil estrategia para posicionar a su discípulo en la corte, evitándose los enfrentamientos directos con cualquiera que pudiera impedir su ascenso en aquel ambiente. Si Pacheco se hubiera inclinado a favor de una u otra posición, la parte contraria se habría mostrado desde aquel momento como una clara opositora a las aspiraciones cortesanas de Pacheco para su yerno. Sin embargo, permanecer al margen, "le va a permitir mantener óptimas relaciones con Rioja y con el entorno de servidores del conde duque, de gran utilidad para el joven Velázquez como es sabido, mientras que conserva sus antiguos vínculos con el duque de Alcalá"72.

71 RODRÍGUEZ GUTIÉRREZ DE CEBALLOS, Alfonso: "El Cristo crucificado de Velázquez: trasfondo histórico religioso", Archivo Español del Arte, 305, 2004, pp. 18-19.

${ }^{72}$ BASSEGODA I HUGAS, B.: Arte de la pintura, op. cit., p. 20. 
Aplicando este mismo razonamiento a la actitud de Velázquez, puede deducirse que quizás este, al pintar el título de la cruz de su Crucificado de San Plácido, seguía el mismo patrón que siguiera su maestro y no quiso arriesgarse a reavivar una nueva polémica que pudiese poner en peligro futuras pretensiones. $\mathrm{Si}$ no actuó de igual modo, un año antes, con el Crucificado de las Bernardas Reales puede deberse a que este otro lienzo pudo realizarse para el disfrute personal del pintor $^{73}$, y no buscara con él agradar con correcciones y formalismos a terceras personas de las que dependieran sus altas aspiraciones ${ }^{74}$.

De los impresos olvidados hasta hoy y conservados en la Biblioteca Nacional bajo las signaturas 2/35639 y 2/18771(2) se desprende que este tema iconográfico del título de la cruz no era desconocido en los ámbitos culturales de la Academia. Tanto los argumentos de Rioja como las razones del duque para justificar su desacuerdo muestran un gran conocimiento de los escritores antiguos. De lo que se deduce que el tema de la iconografía de la crucifixión se venía comentando desde antes del envío de la correspondencia hoy conservada: el duque señala que le consta que el título del Crucificado de Pacheco había sido propuesto por el padre Luis del Alcázar y aprobado por Rioja con anterioridad y esto probaría que la cuestión iconográfica del Crucificado no era un tema de conversación puntual en la Academia, sino que presentaba una continuidad en el tiempo, y que incluso, pudieron existir anteriores documentos sobre este asunto, hoy perdidos.

Fecha de recepción: 30 de septiembre de 2016

Fecha de aceptación: 25 de febrero de 2017

${ }^{73}$ Respecto a la distinción entre imágenes sagradas cuyo uso es público o privado véase el trabajo de RODRÍGUEZ GUTIÉRREZ DE CEBALLOS, Alfonso: "Tipos, usos y abusos de las imágenes sagradas", en Pvlchrvm. Scripta varia in honorem $M^{a}$ Concepción García Gainza. Pamplona, 2011, pp. 718-725.

${ }^{74}$ Véanse las apreciaciones de CRUZ VALDOVINOS, José Manuel: Velázquez. Vida y obra de un pintor cortesano. Zaragoza, 2011. 